\title{
Qual capacidade crítica? Relendo Luc Boltanski à luz de Margaret Archer*
}

\author{
Luiz Augusto Campos**
}

Resumo: A chamada "sociologia da capacidade crítica" de Luc Boltanski vem se tornando um dos principais paradigmas teóricos de interpretação das relações sociais. Contrário ao modo como a sociologia crítica à la Bourdieu entende a reflexividade humana, Boltanski propõe tratar os indivíduos como seres reflexivos, plenamente capazes de julgar e criticar o mundo. No entanto, essa "capacidade crítica" funciona em sua sociologia mais como premissa teórica do que como objeto concreto de investigação. Diante disso, este texto argumenta que uma sociologia interessada na capacidade crítica dos sujeitos não pode apenas "supô-la", deve constituí-la em objeto de estudo sociológico. Para tal, propõe-se reconceituar a capacidade crítica como competência reflexiva, no sentido dado à expressão pela socióloga inglesa Margaret Archer. O recurso às categorias de Archer não apenas ajuda a identificar os limites da sociologia de Boltanski, mas, sobretudo, permite ampliar o seu alcance.

Palavras-chave: reflexividade, sociologia da capacidade crítica, conversações internas, Luc Boltanski, Margaret Archer.

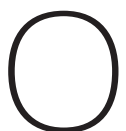

papel da reflexividade nas relações sociais tem constituído um dos mais antigos temas de discórdia da teoria social. Das divergências teóricas mais viscerais do campo - relativas à oposição entre "estruturalistas" e "individualistas", "objetivistas" e "subjetivistas" etc. - até as propostas de reconciliação do alcunhado "novo movimento teórico" (Alexander, 1987), todas parecem ecoar opiniões contraditórias sobre a importância sociológica da reflexão humana. É curioso observar, contudo, que embora essas dicotomias e esses projetos de coadunação estejam perdendo o poder de enquadrar as polêmicas teóricas da sociologia, o tema da reflexividade tem atraído mais e mais atenção.

Isso é notável até mesmo em contextos historicamente pouco afeitos ao conceito, como é o caso da academia francesa. Após décadas de hegemonia de estruturalistas, pós-estruturalistas, estruturalistas construtivistas etc., pode-se dizer que a sociologia na França vive uma "virada pragmatista" (Dosse, 1997). Iniciada por autores como Luc Boltanski, essa guinada reagiu ao automatismo característico dos agentes que povoam parte da sociologia tradicional, em específico os trabalhos de Pierre Bourdieu.

Em seus primeiros textos pós-bourdieusianos, a maioria escrita em parceria com Laurent Thevenot ${ }^{1}$, Boltanski ataca o desdém que a sociologia crítica de Bourdieu

\footnotetext{
* Uma versão preliminar deste artigo foi discutida na XII Conferência Anual da Associação Internacional para o Realismo Crítico, ocasião em que sugestões valiosas permitiram reestruturar o texto. Gostaria também de agradecer a Frédéric Vandenberghe pelos comentários baseados em outra versão do artigo. Agradeço também aos pareceristas anônimos indicados por Sociedade e Estado, cujos comentários ajudaram a tornar algumas passagens mais claras.

** Professor de sociologia do Instituto de Estudos Sociais e Políticos da Universidade do Estado do Rio de Janeiro (lespUerj), doutor em sociologia pela mesma instituição. Coordenador do Grupo de Estudos Multidisciplinares da Ação Afirmativa (Gemaa). Publicações recentes: "A identificação de enquadramentos através da análise de correspondências: um modelo analítico aplicado à controvérsia das ações afirmativa raciais na imprensa", Opinião Pública v. 20, n. 2, 2014;
} 
"Quando a teoria vira fetiche (Resenha de $O$ Fetichismo do conceito), História, Ciências, SaúdeManguinhos, v. 20, 2013; "O pardo como dilema político", Insight Inteligência, v. 63, 2013; "We have a dream. Cientistas sociais e a controvérsia sobre as cotas raciais na imprensa", Revista de Sociologia e Política, v. 20, 2012; "As trocas de acusações entre intelectuais na controvérsia pública acerca das cotas raciais", Latitude, $\mathrm{v}$. 2, 2008; em parceria com João Feres Jr., "Ação afirmativa, comunitarismo e multiculturalismo: relações necessárias ou contingentes?", Revista Brasileira de Ciências Sociais, v. 29, 2014; em parceria com João Feres Jr. \& Verônica Daflon, "Administrando o debate público: o Globo e a controvérsia em torno das cotas raciais", Revista Brasileira de Ciência Política, v. 11, 2013. <lascampos@iesp. uerj.br>

1. Não obstante as bases da sociologia da justificação tenham sido lançadas por obras escritas por Boltanski e Thévenot, passarei a mencionar apenas Boltanski. Além da maior notabilidade de Boltanski em relação ao seu principal parceiro intelectual, utilizarei como base da argumentação alguns trabalhos que foram escritos após nutria em relação à capacidade que os indivíduos têm em julgar reflexivamente a realidade social (Boltanski \& Thévenot, 1983; 1989; 1991; 1999). Para Boltanski, a realização epistemológica dessa "sociologia crítica" baseava-se na injustificada suposição de que o sujeito do conhecimento sociológico dispunha de capacidades críticas muito superiores àquelas dos demais atores sociais. Assim, a sociologia crítica esposaria uma epistemologia que atribui ao sujeito do conhecimento a capacidade e a missão de criticar as estruturas sociais, ao mesmo tempo em que encarava os agentes sociais como seres incapazes de refletir de forma crítica sobre a realidade social em que viviam (Boltanski \& Thévenot, 1999: 24).

Para solucionar essa antinomia teórica, Boltanski propõe que as críticas e denúncias realizadas pelos indivíduos sejam levadas a sério e tomadas como objeto específico de estudo (Boltanski, 1990a). Isso só seria possível caso se admitisse que os indivíduos não são meros agentes coagidos (e constituídos) por violências simbólicas ou, para usar o adágio de Harold Garfinkel, caso se aceitasse que os atores não dispõem de um "juízo dopado" (Garfinkel, 1984). No lugar de uma antropologia filosófica plena de automatismos, dever-se-ia encarar os atores sociais como seres dotados de avançadas competências reflexivas de julgar e criticar a realidade (Boltanski \& Thévenot, 1999: 360).

Todavia, se conceituarmos "capacidade" como qualquer competência, habilidade ou qualidade socialmente adquirida, necessária para performar uma determinada ação (Sen, 2001), logo perceberíamos que Luc Boltanski não faz propriamente uma sociologia da "capacidade" crítica. Isso ocorre não apenas porque sua sociologia "não parece levar em conta as condições sociais do exercício ou da formação das capacidades reflexivas e críticas que pressupõe" (Celikates, 2012), mas também porque a ênfase dada às argumentações dos atores evidencia o maior interesse do sociólogo francês pelas consequências dessa reflexividade do que por ela mesma. Considera-se que todos os indivíduos possuam uma capacidade de criticar mais ou menos equânime, sem atinar para as variações sociológicas dessa reflexividade crítica.

Em resumo, a dita "sociologia da capacidade crítica" não está interessada na natureza da reflexão, mas sim em seus efeitos presumidos e verificáveis na atividade performática do protesto. Consequentemente, Boltanski atribui aos atores sociais uma onicompetência crítica, o que faz com que ele enxergue a crítica como potencialidade onipresente nas relações sociais. Ao termo, a capacidade crítica funciona mais como pressuposto teórico do que como objeto concreto de estudo.

Este texto argumenta que para entender os limites e as potencialidades da capacidade crítica dos atores, é preciso entendê-la não como premissa sociológica, mas como objeto de estudo sociológico. Para tal, pode ser útil tomar a "capacidade 
crítica" como "competência reflexiva" nos termos definidos pela socióloga inglesa Margaret Archer (2000; 2003; 2007; 2010). Com o intuito de captar o papel da reflexividade na reprodução e na transformação sociais, Archer a reconceitua como o conjunto de conversas interiores que temos com nós mesmos. Seria a partir dessas conversas que cada um encabula consigo mesmo que os indivíduos resolvem problemas cotidianos, compatibilizando intenções e desígnios individuais com necessidades e constrangimentos estruturais (Archer, 2007).

Entender que a crítica - de que nos fala Boltanski - emerge das conversas interiores - de que nos fala Archer - permite romper com a naturalização da competência reflexiva promovida pelo sociólogo francês. Mas não apenas isso: tal amálgama teórico ajuda a flexibilizar a maneira algo essencialista com que Margaret Archer lida com os "padrões" de reflexividade. Nesse sentido, são recíprocas as contribuições das duas teorias para uma melhor compreensão do lugar da reflexividade na reprodução e transformação das relações sociais.

O argumento está distribuído em quatro seções. A primeira resume as linhas fundamentais da dita "sociologia da capacidade crítica", proposta por Luc Boltanski, bem como algumas de suas principais insuficiências. A segunda seção apresenta a sociologia dos modos de reflexão de Margaret Archer, sublinhando as contribuições que ela estende à sociologia boltanskiniana. Na terceira, discuto como tal combinação teórica pode ser útil, não apenas para uma sociologia interessada em estudar a capacidade crítica dos atores, mas também para melhor entender a relação entre crítica e reflexividade. Ao termo, delineio algumas consequências gerais desse concerto teórico.

\section{Luc Boltanski:}

\section{uma sociologia da capacidade crítica?}

A sociologia de Luc Boltanski nasce da tentativa de articular, num mesmo quadro teórico, os achados de algumas de suas pesquisas pretéritas. Temática e metodologicamente bem distintas, tais pesquisas englobam objetos que vão desde litígios trabalhistas (Boltanski \& Thévenot, 1989) a reclamações enviadas a jornais por seus leitores (Boltanski, Darré \& Schiltz, 1984), desde a legitimação estatística de categorias socioprofissionais (Boltanski, 1982) até a forma como atribuímos uma dada identidade social a outras pessoas (Boltanski \& Thévenot, 1983).

Mas, a despeito dessa pluralidade de abordagens e temas, todas essas pesquisas têm em comum a intenção de interpelar a maneira como os indivíduos lidam com situações problemáticas, em que seus modos de ver e avaliar o mundo parecem não mais se ajustar a ele. Nesses momentos críticos, rompe-se o acordo tácito que o fim da cooperação teórica. Ademais, os argumentos colocados neste texto parecem não se aplicar à sociologia produzida por Laurent Thévenot depois da ruptura com Luc Boltanski e da "virada pós-humanista" que o caracteriza (Ver Frédéric Vandenberghe, 2006, nota 8). 
garante as rotinas sociais e nossa cooperação com os outros (Boltanski \& Thévenot, 1991: 30). Mais do que situações extemporâneas, as reações nesses momentos diriam muito sobre as bases que constroem e justificam moralmente os vínculos sociais, pois é a partir delas que os indivíduos submetem ao escrutínio as convenções e os acordos que estabilizam suas interações.

Por isso, antes de falar em "grupos", "classes sociais", "Estado", "nações", "operários", "burgueses", "movimentos sociais" etc., a sociologia deveria entender que todas essas categorias estabilizam os vínculos sociais de um dado modo e estão conectadas a convenções e valores morais específicos (ver Boltanski, 1982). Mais importante ainda é o fato de essas categorias serem constantemente contestadas, reconstruídas e adaptadas nas situações diversas em que são mobilizadas. Situações problemáticas envolveriam a capacidade humana de contestar a generalidade e a universalidade desses termos (Boltanski \& Thévenot, 1991: 12). Sempre que um momento crítico surge, a adequação e a moralidade das regras sociais são questionadas. Tal crise só pode ser solucionada caso todos entrem em acordo sobre as razões que justificam uma dada distribuição.

Importa destacar que esses princípios valem tanto para problemas de adequação em relação ao mundo objetivo quanto às relações com os outros sujeitos. Logo, sempre que a adequação de nossas categorias ao mundo objetivo e às relações humanas é posta em xeque, surge não apenas um problema de conformidade de nossas expectativas em relação ao mundo (justesse), mas também de validade das nossas perspectivas morais sobre ele (justice) (Boltanski, 1990a: 105-118; Boltanski \& Thévenot, 1989). Analogamente, tais princípios valem tanto para controvérsias de alcance público como para situações prosaicas, em que o acordo sobre a definição da situação é questionado:

Ocupemo-nos de um problema bem comum: o de como, no decorrer de uma refeição, distribuir a comida entre os convidados. Quando a mesa é grande, os convidados não podem servir-se sozinhos, como fazem em um buffet meal. No decorrer da refeição, a questão da ordem do serviço não pode ser evitada. [...] [Em casos como esses,] a ordem temporal do serviço é suscetível de ser interpretada como uma ordem de precedência de acordo com a importância ou a grandeza relativa dos convidados. Porém, o cumprimento dessa ordem pode ser dificultado, particularmente quando surge a possibilidade da existência simultânea de diferentes ordens de grandeza. É melhor apresentar as iguarias primeiro à avó ou ao chefe do anfitrião? A possibilidade de protesto origina-se da presença, na mesma situação, de diferentes ordens possíveis. Um acordo tácito entre os participantes acerca da espécie de qualidades que deve ser enfatizada pela ordem do serviço é a condição de um evento harmonioso e sem dificuldades. Mas a pré-condição 
deste acordo é um reconhecimento comum de uma equivalência convencional que possa sustentar um juízo acerca da importância ou grandeza relativa das pessoas envolvidas. Mesmo se a referência a essa convenção não seja explícita, ela deve ser clara (Boltanski \& Thévenot, 1999: 363).

Em suma, o modo como os atores sociais reproduzem, reavaliam e retomam o acordo entre si depende de modelos capazes de definir a importância de cada objeto e sujeito envolvido na situação problemática. Esses modelos funcionam como gramáticas morais capazes de estabelecer a ordem de grandeza entre todos esses elementos. Ao contrário do universalismo formal, que acredita que todo acordo se sustenta em um princípio transcendental, e do pluralismo ilimitado, que defende que cada grupo social reconhece valores incomensuráveis em relação aos outros, Boltanski propõe que o acordo costuma basear-se em um conjunto delimitado de "ordens de grandeza" e, logo, em um pluralismo moral limitado (Boltanski \& Thévenot, 1991: 85-90).

Dentro desse pluralismo limitado, Boltanski identifica inicialmente seis modelos ideais de fundamentação de acordos, chamados por ele de cités (Boltanski \& Thévenot, 1991: 27). Inspirado na teoria das esferas de justiça de Michael Walzer (2003), ele propõe que cada uma dessas cités constitui uma gramática moral que permite aos atores fundamentarem seus acordos sociais e submetê-los à crítica (Boltanski \& Thévenot, 1991: 28).

Para sistematizar as características fundamentais de cada cité, Boltanski recorre a obras clássicas da filosofia moral que, a seu ver, oferecem uma concepção geral e ideal do mundo e que, assim, servem para que os indivíduos possam ordenar suas relações. Haveria uma "cité da inspiração", na qual pessoas e objetos são julgados por sua criatividade e imaginação, cité própria dos artistas e gênios, cuja gramática principal se encontra na Cidade de Deus de Santo Agostinho; uma "cité doméstica", onde tradição e hierarquia são valores centrais e os "grandes" são os pais e familiares, cuja sistematização modelar encontra-se na obra de Bossuet; uma "cité da opinião" baseada no renome e na reputação tal como tratados no capítulo dedicado à honra no Leviatã de Thomas Hobbes; uma "cité cívica", no âmbito da qual o bem comum é o valor fundamental e cujo Contrato social de Rousseau serve de modelo; uma "cité mercadológica" baseada na concorrência e na rivalidade, tal como apresentadas por Adam Smith; e, por fim, uma "cité industrial" baseada na eficácia e produtividade própria da utopia saint-simoniana (Boltanski \& Thévenot, 1991: 85-105)².

Não é o objetivo aqui discutir em detalhe o modelo das cités, embora essa pareça ser a parte mais influente da sociologia de Boltanski (Dodier, 2005). Interessa particularmente como essa sociologia, preocupada com a justificação dos acordos
2. Posteriormente, Luc Boltanski e Éve Chiapello adicionarão ao modelo uma sétima cité, própria do capitalismo avançado: a cité dos projetos (Boltanski \& Chiapello, 2009). 
sociais, está construída sobre uma antropologia filosófica que atribui aos indivíduos uma enorme capacidade reflexiva (Bénatouïl, 1999). Se as situações problemáticas, das arengas mais comezinhas às controvérsias públicas, são resolvidas a partir de complexas operações de construção de equivalências e atribuições de grandezas, tudo orientado por gramáticas morais quase filosóficas (as cités), os indivíduos são vistos como dotados de uma enorme capacidade de julgar reflexivamente o mundo. Nos termos de Boltanski \& Thévenot,

[...] o que é pertinente para o argumento é a reflexividade do momento crítico. A situação inicial é mais ou menos a seguinte: as pessoas, envolvidas em relações costumeiras, fazendo coisas juntas - a saber, em política, trabalho, sindicalismo - e tendo que coordenar suas ações, dão-se conta de que há algo errado; que elas não conseguem mais conviver; que algo mudou. Dar-se conta de algo possui uma dupla significação. O termo aponta ao mesmo tempo para um movimento reflexivo interior e para uma performance no mundo exterior. No processo de se dar conta de que algo está errado deve-se tomar distância do momento presente e retroceder ao passado (Boltanski \& Thévenot, 1999: 359-360).

3. Além deste, o autor fala em "sociologia da justificação",

"sociologia da moral", "sociologia da crítica" etc. Posteriormente, enfatizarei que esses títulos traduzem melhor a teoria de Boltanski do que a expressão "sociologia da capacidade crítica".

4. Inúmeras são as obras em que Bourdieu discute a importância da crítica sociológica e suas fundamentações teóricas. No entanto, uma síntese dessa "postura" política e epistemológica pode ser encontrada em sua entrevista concedida a Axel Honneth (Bourdieu, 2004)
É justamente por isso que, dentre os vários títulos que Boltanski confere à sua teoria, está o de "sociologia da capacidade crítica" ${ }^{3}$. Essa sociologia contrapõe-se basicamente à dita "sociologia crítica" de Bourdieu", particularmente pelo fato de conjugar uma concepção positivista da neutralidade científica com a exigência de que o sociólogo assuma uma missão crítica perante a sociedade (Boltanski, 1990b; Boltanski \& Thévenot, 1991: 24). Essa combinação político-epistemológica conferiria ao sociólogo uma competência reflexiva superior, que o habilitaria a julgar as relações sociais do exterior. Além disso, ela assumiria um compromisso normativo, mas sem reconhecê-lo como tal, já que a crítica social é considerada como obrigação imposta pela própria ontologia do objeto sociológico. Mais problemático ainda é o fato de esse messianismo positivista ser justificado por uma antropologia filosófica que subtrai dos atores sociais a capacidade crítica, o que supostamente faria Bourdieu com o conceito de habitus (Boltanski, 2009).

Contra a atrofia da capacidade crítica dos atores e contra a hipertrofia da capacidade crítica do sociólogo, Boltanski propõe simetrizar "latournianamente" (Latour, 2005) sujeito e objeto do conhecimento sociológico, conferindo aos atores sociais capacidades críticas equivalentes àquelas reivindicadas pelos cientistas (Boltanski \& Thévenot, 1999). A princípio, todos seríamos onicompetentes para classificar e julgar reflexivamente a realidade:

A formulação de uma crítica supõe, preliminarmente, uma experiência desagradável que suscite a queixa, quer ela seja vivenciada 
pessoalmente pelo crítico, quer este se comova com a sorte de outrem. A isso damos aqui o nome de fonte de indignação. Sem esse primeiro impulso emotivo, quase sentimental, nenhuma crítica consegue alçar voo. Em contrapartida, há grande distância entre o espetáculo do sofrimento e a crítica articulada; o crítico precisa de um respaldo teórico e de uma retórica argumentativa para dar voz ao sofrimento individual e traduzi-lo em termos que façam referência ao bem comum. É por isso que existem realmente dois níveis na expressão de uma crítica: um nível primário, da esfera das emoções, que é impossível calar e sempre está pronto a inflamar-se desde que se apresentem novas situações que forcem a indignação; e um nível secundário, reflexivo, teórico e argumentativo, que possibilita sustentar a luta ideológica, mas pressupõe recurso a conceitos e esquemas que permitam vincular as situações históricas que se pretendam submeter à crítica a valores passíveis de universalização (Boltanski \& Chiapello, 2009: 72).

O fato de os atores serem competentes para formular uma crítica reflexivamente aproxima as práticas cotidianas das práticas científicas. Em um de seus estudos, Boltanski propôs que algumas pessoas adivinhassem o lugar social (basicamente, a profissão) de um indivíduo real, mas do qual elas conheciam apenas características gerais como renda, educação, gostos etc. (Boltanski \& Thévenot, 1983). Para ele, experimentos como esse permitiriam perceber que pessoas comuns frequentemente "se parecem com estatísticos ou pesquisadores munidos de leis sociais" (Boltanski \& Thévenot, 1991: 17) $)^{5}$. Daí a necessidade de romper com a sociologia crítica em nome de uma sociologia da capacidade crítica (Boltanski \& Thévenot, 1999).

Todavia, se entendermos por "capacidade" o conjunto de competências, habilidades ou características socialmente adquiridas que são necessárias para realizar uma dada prática, tarefa ou performance socialmente valorizada (Sen, 2001), perceberemos que Boltanski não faz propriamente uma sociologia da "capacidade" crítica, a despeito do título que ele formula para sua teoria (Celikates, 2012). Não obstante Boltanski ressalte que "o que é pertinente para o argumento é a reflexividade" e que "operações de acumulação e cálculo" sejam "requeridas para culpar e criticar" (Boltanski \& Thévenot, 1999: 360), pouco é dito por ele sobre o funcionamento concreto dessa reflexividade. A ênfase de suas pesquisas nas argumentações dos atores em situações problemáticas consegue, no máximo, captar os efeitos dessa reflexividade. Isso evidencia o pressuposto de que todos os indivíduos que denunciam possuem uma capacidade de criticar equânime. O interesse é, portanto, deslocado da natureza mesma da reflexividade para a atividade performática de protesto, em específico, para a expressão verbal do protesto.

Em suma, pouco é dito sobre a capacidade crítica em si, categoria muito mais próxima de uma premissa metodológica do que de um objeto de estudo. Ainda que as
5. Ève Chiapello, uma das colaboradoras de Boltanski, é mais enfática ao afirmar que "isso significa que a todos os seres humanos devem ser garantidas as mesmas capacidades elementares dos cientistas sociais quando se trata de questionar ideologias e representações sociais" (Chiapello, 2003: 157). 
6. Em uma obra mais recente, em que Boltanski tenta compatibilizar sua sociologia com a crítica social, tal "automatismo da crítica" é matizado. Ele percebe, por exemplo, a centralidade das condutas realistas, que reconhecem o desencaixe de determinadas situações, mas não as submetem à crítica dada a pequena possibilidade de que alguma mudança advenha dessa reação (Boltanski, 2009). Contudo, o autor permanece insensível à possibilidade da crítica silenciosa, sobre a qual falaremos em seguida. pesquisas empíricas de Boltanski possam nos convencer de que esta competência de julgamento realmente se faz presente em "momentos críticos", o nível de abstração de sua sociologia e a natureza do material sobre o qual ele se apoia pouco dizem sobre os limites, as potencialidades e as características da capacidade crítica. Consequentemente, seria mais apropriado subtrair o termo "capacidade" do rótulo dado à sua teoria e defender que Boltanski constrói uma "sociologia da crítica", isto é, de suas exigências formais, principais sentidos, conteúdos etc.

Ora, uma sociologia que se ancora na capacidade crítica dos indivíduos não pode abster-se de pesquisar as características dessa competência, mormente as condições que potencializam ou inibem a sua emergência e expressão. Ao analisar a sociologia experimental de Garfinkel (2010), interessada nas reações dos indivíduos em situações que fogem à normalidade, Boltanski ocasionalmente dá a entender que são as próprias situações que levam a performances críticas. Ou seja, que é o simples rompimento da normalidade das situações ou da reciprocidade de expectativas que torna a crítica uma consequência forçosa (Boltanski, 1990a: 22). Dessa perspectiva, a emergência da crítica é vista quase como uma reação necessária, curiosamente, como uma reação quase "irrefletida" 6 :

A pessoa que se dá conta de que algo não está funcionando raramente permanece em silêncio. Ela não guarda os seus sentimentos para si. [...] A pessoa deve, por essa razão, expressar descontentamento em relação às outras com quem estivera desempenhando, até então, uma ação conjunta (Boltanski \& Thévenot, 1999: 360, grifos meus).

Ao atribuir uma onicompetência crítica aos indivíduos, Boltanski termina por considerar a crítica uma potencialidade onipresente no ser social. Ao mesmo tempo, tende a confundir a emergência da crítica com sua expressão verbal.

Romper com essa "suposição da reflexividade indiscriminada" (Giddens, 1991: 39) passa por uma definição de reflexividade que permita entender quando e porque a crítica emerge. Para além da situação problemática, deve-se conjecturar quais as características de cada ator influenciam na emergência da crítica. Nesse sentido, acredito ser útil reconceituar o que Boltanski chama de "capacidade crítica" como "competência reflexiva", nos termos da socióloga inglesa Margaret Archer. Para meIhor entender como esse empréstimo teórico contribui para a construção de uma sociologia da reflexividade crítica, é preciso, antes, apresentar em linhas gerais os fundamentos da teoria social de Archer. 


\section{Margaret Archer: os tipos de reflexividade}

Não é apenas na França que o debate acadêmico vem se concentrando em volta do tema da reflexividade. O mesmo parece acontecer com a sociologia inglesa. Embora o conceito já frequentasse há bastante tempo as obras de Anthony Giddens e de seus parceiros de pesquisa, mormente Ulrich Beck e Scott Lash (Beck, Giddens \& Lash, 1997; Giddens, 1991; 2003), a noção de reflexividade parece ser utilizada para fazer referência ora a uma propriedade estrutural da modernidade, ora a uma competência individual. Em Giddens, a reflexividade típica da modernidade teria menos a ver com a capacidade humana de refletir sobre problemas e mais com a dupla hermenêutica existente entre a sociedade como um todo e os sistemas peritos (ver Giddens, 1991: 41-55).

A crítica de Margaret Archer a Anthony Giddens segue nesse sentido. Segundo Archer, ao entender o "dualismo" entre estrutura e agência como dualidade (Giddens, 2003), Giddens estaria apenas fundindo as duas instâncias em uma ontologia tautológica, produzindo o que ela rotula como "conflação central" (Archer, 1995). Isso levaria o sociólogo inglês a oscilar insidiosamente entre os dois níveis, ora atribuindo características estruturais a indivíduos, ora atribuindo características individuais a estruturas. Por isso tudo, Archer assevera que

não é possível atrelar nenhum significado real à noção de reflexividade sistêmica (isto é, a propriedade apropriada pelo sistema social como um conjunto de "partes" institucionais), a qual o conceito de "modernização reflexiva" sugere adjetivamente (Archer, 2007: 30).

Essa visão já permite antever o ponto de partida metodológico da autora, próximo ao realismo crítico desenvolvido por Roy Bhaskar (1998). De maneira geral, Archer se filia à corrente ao partilhar o pressuposto de que os polos opostos da ontologia social - estrutura e agência - não devem ser reduzidos um ao outro, muito menos acoplados através de esquemas de dualidade estrutural como aquele proposto por Anthony Giddens (Archer, 2003). Determinar em que medida as estruturas impactam na agência dos indivíduos e vice-versa dependeria da manutenção analítica da divisão ontológica entre estrutura e ação como propriedades emergentes, irredutíveis entre si (Archer, 1995). E é justamente aqui que o conceito de reflexividade entra em cena. A reflexividade - para Archer - é o lócus onde os interesses individuais são conciliados com contextos diferentes ou onde o espaço da agência é compatibilizado com os constrangimentos estruturais (Archer, 2003).

Ao recuperar a pragmática da mente humana de George Hubert Mead (1967), Archer define a reflexividade como o conjunto das conversações interiores que um 
indivíduo tem consigo mesmo, isto é, as meditações reflexivas que mantemos com nós mesmos sempre que temos de resolver problemas cotidianos (Archer, 2007). Através dessas conversações internas, os indivíduos refletem sobre a melhor forma de alcançarem seus interesses. Esses modos de reflexividade são

\begin{abstract}
propriedades relacionais derivadas de diferentes combinações da interação entre "contextos" e "interesses", mas que não podem ser reduzidas a cada uma dessas instâncias (Archer, 2007: 63).
\end{abstract}

Assim, há entre estrutura e ação uma intermediação, um momento em que paramos, pensamos, mobilizamos nossas categorias cognitivas e, segundo orientações reflexivas, "trilhamos nosso caminho no mundo" (Archer, 2007: 5). Destarte, é a reflexividade como conversações internas que realiza a mediação (sem conflação) entre estrutura e agência.

A partir de uma pesquisa empírica que buscou relacionar padrões de mobilidade social a modos de reflexividade, Archer formula tipos analíticos de conversação interior (Archer, 2007). Esta pesquisa investigava, especificamente, a forma como os indivíduos compatibilizavam suas escolhas profissionais com seus anseios mais íntimos, de um lado, e as demandas de um dado contexto, do outro. Archer destaca

7. Posteriormente, ela adicionará à tipologia uma quarta alternativa, a "reflexividade fraturada" (Archer, 2012). Ignoro aqui este adendo à tipologia não apenas por ele não pertencer às obras principais da autora, mas também porque não estou certo de que constitua um "tipo" efetivo de reflexividade, mas sim um conjunto de reflexividades mais plurais e heterogêneas. que os atores pesquisados por ela costumavam adotar três padrões reflexivos ${ }^{7}$ para resolverem o dilema ocupacional supracitado:

1. mediante conversas exteriores com amigos ou parentes, isto é, pedindo opiniões, conselhos, indicações;

2. de maneira solitária, porém estratégica, visando compatibilizar interesses individuais com contextos específicos sem, contudo, acreditar na legitimidade da opinião alheia; ou ainda

3. de forma muito intensa e, às vezes, sofrida, ininterrupta, questionando mesmo em que medida determinados caminhos levariam a uma maior ou menor autorrealização pessoal (Archer, 2007: 269-313).

A autora chama o primeiro tipo de padrão reflexivo de "comunicativo reflexivo", o segundo de "autônomo reflexivo" e o terceiro de "metarreflexivo".

Cada um de nós teria um padrão dominante de reflexividade e cada tipo de reflexivo teria poderes causais diferenciados na mudança/reprodução das estruturas sociais (Archer, 2007: 16-22). Os comunicativos reflexivos seriam aqueles que acreditam que refletem melhor quando dividem seus pensamentos e angústias com outras pessoas (Archer, 2007: 102). Estas, por seu turno, devem ser preferencialmente similares e familiares, pois parte-se da premissa de que só quem tem visões semelhan- 
tes ou já passou por problemas análogos terá condições de ajudar (Archer, 2007: 104). Por isso, os comunicativos teriam uma maior imobilidade social e geográfica, já que seriam excessivamente dependentes dos conselhos de seus familiares (Archer, 2007: 101). Resumidamente, aqueles que precisam "conversar para pensar" e, por isso, são excessivamente dependentes de seus interlocutores imediatos, tenderiam a se tornar "agentes passivos" (Archer, 2007: 275), o que minaria suas oportunidades de mobilidade social.

Já os autônomos reflexivos seriam os que privilegiam as conversações internas estratégicas e solitárias (Archer, 2007: 114). Se os comunicativos reflexivos têm grande respeito pela incerteza do futuro e, por isso, procuram se informar sobre planos, sucessos e fracassos dos que os rodeiam, os reflexivos autônomos são domadores da incerteza futura, pois creem que podem pensar em todas as possibilidades de ação, resultados possíveis, variáveis em jogo. São planejadores inveterados (Archer, 2007: 286). No entanto, isso não quer dizer que os autônomos tendem necessariamente a romper a imobilidade social dos comunicativos, ao contrário, demonstram grande dificuldade na transição da escola para a vida profissional, pois esse período demanda que o autônomo reflexivo traduza suas habilidades práticas adquiridas e desenvolvidas solitariamente em habilidades socialmente reconhecidas e institucionalizadas (Archer, 2007: 121). Entretanto, uma vez que as competências desenvolvidas se encaixam nas estruturas ocupacionais disponíveis, o autônomo reflexivo em geral experimenta uma brusca mobilidade social.

Além dos dois tipos acima mencionados, Archer cita um último: os metarreflexivos, isto é, aqueles que refletem sobre a própria reflexão (Archer, 2007: 93) e que, por isso, não só conversam consigo mesmo de forma solitária, mas basicamente o tempo inteiro e de forma intensa. Os autônomos reflexivos apresentam um padrão de conversação interior mais focado nos meios para atingir um dado fim e, por isso, tendem a parar a reflexão quando o problema em questão é solucionado. Já os metarreflexivos estão mais preocupados com a decisão certa em termos de valores do que com a decisão melhor em termos de ganhos (Archer, 2007: 229). Por refletirem sobre os valores, tendem a negar as opções e os caminhos já conhecidos e não investem na ordem social (como os comunicativos), nem na ordem prática (como os autônomos), mas numa ordem transcendental (Archer, 2007: 231). Por isso metarreflexivos não aspiram somente à realização profissional, mas, sobretudo, à realização total de suas vidas pela profissão.

Existem muitas semelhanças entre a teoria social de Boltanski e a de Archer. A mais evidente é a preocupação com a reflexão produzida pelo bloqueio de uma ação rotinizada. Nesse ponto, ambos partilham de uma concepção pragmatista que enxerga os sujeitos como seres dialógicos, cuja reflexividade é ativada sempre que situações 
problemáticas e não familiares surgem. No entanto, o tipo de deliberação reflexiva enfocada por cada autor difere. Enquanto Archer enfatiza as deliberações internas que surgem da ruptura da prática, Boltanski está mais atento às deliberações externas que surgem nessas situações críticas.

Curiosamente, essa diferença de foco reflete apropriações particulares que os dois autores fazem da obra de George Hubert Mead (1967). Tanto Boltanski quanto Archer incorporam de Mead o pressuposto geral de que o desenvolvimento dos sujeitos acompanha o desenvolvimento da linguagem. O que diferencia os seres humanos dos animais - para Mead - é o fato de nossos "gestos vocais" (vocal gestures) serem capazes de gerar efeitos previstos nos outros porque todos concordamos com o significado atribuído a eles (Mead, 1967: 42-48).

Em seu exemplo clássico, Mead argumenta que o latido de um cão pode fazer com que outro cão mude sua ação num dado momento (pare de correr, comece a correr, pare de latir, comece a latir também etc.). Porém, esses gestos não são significantes porque o latido do primeiro cachorro não produz consequências mais ou menos esperadas no segundo. O desenvolvimento de uma criança até a vida adulta acompanha essa adaptação entre os gestos vocais e as suas consequências no comportamento alheio. Com o tempo, tal adaptação faz com que os indivíduos percebam que os outros não reagem de forma totalmente arbitrária aos seus gestos, que existe uma espécie de acordo entre esses outros, o que compõe em suas mentes um "outro generalizado" (Mead, 1967: 152).

Para o autor, essa habilidade de antecipar as consequências de um ato de fala nasce não apenas da maior complexidade lógica da linguagem humana, mas do simples fato de que somos capazes de ouvir o que falamos e, assim, entender como os outros nos ouvem (Mead, 1967: 50). Isso nos confere um controle maior sobre nossas expressões vocais e, sobretudo, a capacidade de falar com os outros mesmo quando eles não estão presentes. Tão relevante quanto ouvir as nossas "conversas externas" (com os outros) é a capacidade de conversamos internamente com nós mesmos, o que constitui o que entendemos como mente (Mead, 1967: 52).

Boltanski incorpora de Mead a ideia de que o self se desenvolve a partir desse acordo tácito entre cada um de nós e um outro generalizado, acordo que ocasionalmente é rompido e, por isso, precisa ser retomado (Boltanski \& Thévenot, 1991: 82). Seus estudos de situações problemáticas buscam justamente entender como o acordo se fundamenta depois de ser ameaçado. Já Archer está mais interessada na noção de reflexividade enquanto capacidade de conversar internamente (Archer, 2007: 68). Por isso mesmo, a reflexividade opera em Boltanski como um a 
priori que tem de ser pressuposto para que ele possa compreender os acordos e desacordos sociais como resultantes da dialética entre ações rotinizadas que se desenvolvem em um "regime de paz", e as ações que são submetidas às exigências de justificação ou a um "regime de justiça" (Boltanski, 1990a: 105-118). Por outro lado, há de se notar ainda que o foco de Archer faz com que ela perca de vista a dimensão mais interacionista e os efeitos de uma situação nos modos de reflexividade, o que ocasionalmente faz com que sua teoria descambe para um mentalismo exagerado.

De toda forma, uma "sociologia da capacidade crítica" não deve pressupor tal capacidade, mas operar com conceitos que permitam tomá-la como objeto de estudo. Para tanto, acredito ser importante a compreensão da capacidade humana de criticar como competência reflexiva, tal como definida por Archer. Isso pode ter duas implicações fundamentais. A primeira - e a mais importante delas - é que a emergência e expressão da crítica devem ser tratadas como fenômenos distintos. Ao que parece, Boltanski não é capaz de entender os limites da crítica (e da capacidade crítica) justamente por fundir as duas coisas, isto é, ele não percebe que entre a indignação bruta e a crítica articulada (Boltanski \& Chiapello, 2009: 72) existe uma reflexividade crítica silenciosa, mas com efeitos práticos. A segunda implicação é que o tipo de reflexividade crítica que adotamos tende a ser influenciado pela maneira como definimos a situação de disputa vivida. Isso quer dizer que as críticas que proferimos não nascem apenas de uma capacidade reflexiva específica, mas que a nossa capacidade reflexiva sofre mudanças a partir das consequências de nossa performance crítica. Por isso, a leitura combinada da teoria de Boltanski e da teoria de Archer serve não apenas para estender o escopo de aplicação da primeira, como também para reduzir o mentalismo da segunda.

\section{Crítica silenciosa e transições reflexivas}

Incorporar os conceitos de Archer ao modelo de Boltanski é importante para perceber que a mediação reflexiva, posterior a uma sensação de desrespeito, pode se dar de diferentes modos, dependendo do tipo de reflexividade do ator em questão. Isto quer dizer que não é possível pressupor que "a pessoa que se dá conta de que algo não está funcionando raramente permanece em silêncio" (Boltanski \& Thévenot, 1999: 360) ou que ainda "há grande distância entre o espetáculo do sofrimento [a indignação] e a crítica articulada" (Boltanski \& Chiapello, 2009: 72). Entre a indignação e a verbalização da crítica existe um continuum, uma miríade de conversas internas que constituem a reflexividade humana. Por isso, entender a crítica passa por entender que a capacidade de conversar consigo mesmo é o que lastreia a competência crítica.
8. É verdade que Boltanski destaca ocasionalmente que a competência crítica é uma construção histórica. No entanto, suas pesquisas empíricas costumam pressupor capacidades reflexivas quase constantes no decorrer das situações. 
Isso fica mais evidente quando entendemos que muitas das características dos tipos de reflexividade de Archer refletem formas distintas de lidar com a crítica. A insegurança reflexiva que caracteriza o comunicativo reflexivo (Archer, 2007: 198), por exemplo, tem a ver não apenas com o fato de ele atribuir aos seus outros significantes uma maior competência reflexiva. Sua insegurança reflexiva reflete também uma insegurança crítica, isto é, uma desconfiança em relação à sua capacidade de argumentar contra uma situação vista como anormal. Por isso, sempre que uma situação problemática surge, é de se esperar que o comunicativo reflexivo conduza alguns diálogos restritos com os mais íntimos, de modo a colocar à prova o ajuste de suas indignações. Pode-se conjecturar que os comunicativos reflexivos teriam também dificuldade em generalizar suas demandas sem o apoio de outros. De todo modo, essas conjecturas ajudam a compreender que a emergência da crítica tenderia a vir acompanhada de sua expressão restrita, mas não de sua generalização para a esfera pública. Isso é importante para entendermos que a generalização da crítica não depende apenas de um padrão público de normalidade ou de uma competência em mobilizá-lo para generalizar denúncias (Boltanski, Darré \& Schiltz, 1984), mas também das estratégias reflexivas, empregadas pelos atores sociais para resolver situações problemáticas.

É possível conjecturar que algo distinto se passaria com um autônomo reflexivo. Suas conversas internas tendem a orientar-se estrategicamente e, assim, dependem do sucesso de suas consequências. Por isso, um autônomo reflexivo dificilmente sentiria necessidade de partilhar suas angústias com seus familiares antes de expressar sua crítica em uma situação problemática. Outra possibilidade é que ele entre numa curta cadeia de ruminações para avaliar se sua indignação é ou não aceitável perante aqueles com os quais interage. Isso reflete não apenas uma maior segurança reflexiva, mas também uma maior segurança em escrutinar as situações desajustadas. Assim, pode-se esperar desse indivíduo um maior traquejo quando se trata de recorrer, por exemplo, a diferentes ordens de grandeza.

A experiência de indignação de um metarreflexivo, por sua vez, tenderia a ter consequências igualmente particulares. Sua propensão a refletir de forma intensa pode levar tanto a uma crítica elaborada e absorvente como ao completo abandono da situação problemática. Uma crítica articulada, que cumpra as fortes exigências do modelo de Boltanski, é também uma performance custosa para um metarreflexivo. Ela exige um compromisso com uma ordem de grandeza, com uma visão da situação e de seus princípios morais. Essas pesadas exigências podem levar à fuga da situação problemática. Não é gratuito, portanto, que os metarreflexivos tenham um maior índice de mobilidade profissional (Archer, 2007: 121), já que dificilmente conseguem traduzir suas insatisfações reflexivas com ações estratégicas. Por outro lado, a intensidade da metarreflexão pode estar na base da invenção moral que leva 
à emergência de novas ordens de grandeza, processo explorado mais recentemente por Boltanski e Chiapello (2009). Ao não aceitar nenhum dos princípios de construção das equivalências e das grandezas existentes, o metarreflexivo é conduzido a um imperativo de invenção moral, custoso de sustentar, mas que pode tensionar os limites do pluralismo limitado das sociedades complexas.

Essas conjecturas servem para que percebamos que entre a manifestação reservada de indignação e a denúncia pública está a reflexividade, isto é, as conversações internas. Logo, existe entre ambas algo que Boltanski parece ignorar: a crítica silenciosa ou crítica interna. Para esclarecer o que entendemos por essa expressão, convém retomar o exemplo banal, porém elucidativo, da iminência do protesto em um jantar (Boltanski \& Thévenot, 1999: 363). Imaginemos que, nesta situação, chegue a um nível insustentável a "existência simultânea de diferentes ordens de grandeza", ou que nenhum acordo de equivalência tenha ficado claro "o suficiente para produzir uma situação que pareça repousar numa ordem natural" (Boltanski \& Thévenot, 1999: 363). A queixa se dará de forma automática, como Boltanski sugere? Certamente, muitos fatores incidirão na verbalização ou no silenciamento da crítica. Contudo, a conversa interior constituirá o filtro último que definirá sua expressão. Mais importante ainda, a não verbalização da crítica não implica seu desaparecimento. Ela permanecerá presente nas conversas interiores dos envolvidos e poderá ter efeitos práticos relevantes.

Acredito que dois exemplos, extraídos de duas obras sociológicas, ajudam a demonstrar a possibilidade e a importância das críticas silenciosas. O primeiro deles se refere às chamadas "formas cotidianas de resistência", estudadas pelo antropólogo estadunidense James Scott (1990). Crítico do modo como as classes sociais mais exploradas (escravos, camponeses, miseráveis etc.) são analisadas pelas ciências sociais, Scott dedica grande parte de suas obras ao modo como tais grupos resistem à assimétrica dominação de que são vítimas (Scott, 1990). A partir de uma etnografia junto a um pequeno povoado de trabalhadores rurais na Malásia, o antropólogo observa como é difícil que esses trabalhadores se oponham publicamente à exploração a que são submetidos (Scott, 2008). Todavia, a suposição de que as elites agrícolas exercem uma "hegemonia" sobre as mentes desses camponeses ignoraria suas inúmeras formas de resistir silenciosamente, a partir de condutas corriqueiras que visam opor à dominação alguma resistência (sabotagens, corpo mole, indolência, falsa obediência, furtos etc.) (Scott, 2008). Tais relutâncias silenciosas não são triviais pois levam a

uma avalanche social de pequenos atos de insubordinação levados a efeito por uma improvável coalizão de escravos e pequenos proprietários rurais - uma coalizão sem nome, sem organização, sem liderança e, certamente, sem uma conspiração leninista por trás. [...] [Ademais, em contextos de dominação desigual,] furtar-se à 
aquiescência é em certo sentido mais radical, em suas implicações para o exército como instituição, do que a substituição dos oficiais (Scott, 2008).

Vale realçar que esse tipo de resistência não é mecânica e pode em certo sentido ser entendida como um traço rudimentar de crítica silenciosa. Como destaca Scott, ela costuma depender de registros ocultos (hidden transcripts) e de uma subcultura que, em geral, é plena de anedotas, ditados e folclores que diminuem os dominadores:

\begin{abstract}
Os símbolos, as normas, as formas ideológicas que eles criam constituem o pano de fundo indispensável para o seu comportamento. Por parcial ou imperfeito que seja seu entendimento da situação, eles são dotados de intenções, valores e intencionalidades que condicionam suas ações. Isso é tão evidente que dificilmente mereceria ser reafirmado não fosse pela lamentável tendência, nas ciências comportamentais, de inferir o comportamento de massa diretamente dos sumários estatísticos sobre renda, ingestão de calorias, circulação de jornais ou propriedade de estações de rádio (Scott, 2008).
\end{abstract}

Por razões óbvias, essas críticas não apresentam o nível de articulação teórica exigido pelo modelo de Boltanski. Mas, nem por isso, devem ser reduzidas a uma indignação acrítica. Elas constituem um excelente exemplo de como os atores são capazes de se opor a uma dada situação, produzindo discursos críticos a ela, sem, no entanto, expressá-los publicamente. O fato de esse tipo de crítica não poder se verbalizar ou se condensar em registros públicos não nos deve cegar para o conjunto de discursos críticos de uma dominação que não é acessível àqueles que não sofrem com ela (Scott, 1990). Entender as formas cotidianas de resistência como críticas silenciosas ajuda a compreender como a crítica pode ser externalizada na prática e condensada em discursos ocultos sem, contudo, se expressar verbal, pública e estruturadamente.

Outro exemplo de como a crítica pode traduzir-se em prática sem ser comunicada pode ser colhido do trabalho da cientista política alemã Elizabeth Noelle-Neumann. Em The spiral of silence (1993), Noelle-Neumann tenta explicar o incômodo fato de que as posições políticas minoritárias costumam ser sub-representadas nas pesquisas de opinião. Essa subestimação é distribuída de forma mais ou menos uniforme em muitas pesquisas e, por isso, dificilmente pode ser atribuída a problemas metodológicos circunstanciais. Ao partir do postulado de que os indivíduos teriam em geral um "medo do isolamento" (fear of isolation), Noelle-Neumann (1993) sugere que indivíduos que acreditam ter posições políticas minoritárias, vistas como não justificáveis perante outros agentes, tendem a calar ou a mentir quando indagados 
por um pesquisador. Já aqueles que adotam posições políticas mais comuns ou vistas como mais "normais" não teriam a mesma conduta (Noelle-Neumann, 1993).

Contudo, apesar de não pretenderem justificar suas opiniões publicamente, esses mesmos atores têm uma íntima convicção de que suas críticas políticas são legítimas. E, justamente por isso, adotam um comportamento político incoerente com a intenções de voto que manifestam publicamente. Importa notar que os indivíduos calam porque acreditam que suas posições são minoritárias, "desviantes" em relação às posições "normais". Justamente por saberem que a comunicação de suas posições políticas demandará justificações complexas, com pequenas possibilidades de serem aceitas por seus pares, esses atores preferem calar ou mentir sobre elas. Isso não quer dizer que a crítica desse grupo seja totalmente sublimada, pois seu comportamento eleitoral permanece refletindo suas conviç̧ões íntimas (Noelle-Neumann, 1993). Ao termo, os resultados eleitorais costumam contradizer bastante as estimativas anteriores.

Apesar de profundamente diferentes, os trabalhos de John Scott e Elisabeth Noelle-Neumann evidenciam a importância prática do interdito e a reflexividade que pode estar por trás de uma crítica silenciada. É preconceituoso tratar esse tipo de crítica silenciosa como mera indignação bruta, qualitativamente distinta da crítica verbalizada e quase teórica de que fala Boltanski. Como Scott aponta, tais críticas estão atreladas a uma subcultura povoada de discursos articulados, mas que não se expressam por conta da desigualdade estrutural que marca contextos de dominação. Já Noelle-Neumann assevera que a dissimulação dos eleitores extremistas não reflete uma reflexividade fraturada, mas uma consciência da estigmatização de suas identidades políticas.

Mas não é apenas a sociologia da justificação que se beneficia da teoria de Margaret Archer, pois o oposto também ocorre. De modo geral, a ênfase de Archer sobre a relativa independência das conversações interiores faz com que ela perca de vista alguns dos condicionamentos situacionais impostos à reflexividade humana. Um subproduto deste "mentalismo" é a ilação implícita de que os indivíduos apresentam padrões dominantes de reflexividade (Archer, 2007: 86). Encarar a reflexão como um trabalho de crítica interna permite perceber que os próprios padrões de autoconversação estão relativamente condicionados pelos imperativos de justificação situacionais de que nos fala Boltanski (1999: 360).

Dito de outro modo, um ator que apresente um determinado padrão reflexivo pode, em uma situação específica, adotar outra estratégia de autoconversação. Portanto, os modos de reflexividade podem derivar não só "das diferentes combinações da interação entre 'contextos' e 'interesses'” (Archer, 2007: 269), como ainda das situações particulares em que são ativados. Como já foi dito, antes de criticar, o indivíduo passa 
por um processo mais ou menos solitário de avaliação da legitimidade de suas inquietações. Esse processo pode culminar na crítica verbal propriamente dita ou ser simplesmente silenciado sem, no entanto, desaparecer. É comum também que a crítica seja adiada por minutos, dias, meses e até mesmo anos. Uma situação que, por exemplo, pode parecer imprópria para manifestações de indignação é capaz de desencadear uma longa conversação interior num indivíduo que não esteja acostumado a uma reflexividade silenciosa. Consequentemente, os padrões de conversações internas de Archer talvez possam ser mais bem compreendidos in situ em vez de serem considerados apenas como características estáveis e pessoais.

As conversas internas são fundamentais para a reavaliação por parte do indivíduo do grau de reconhecimento social dos imperativos de justiça por ele internalizados. Sucessivas performances críticas mal sucedidas para um autônomo reflexivo excessivamente estratégico, por exemplo, podem levar a uma total reavaliação de suas estratégias reflexivas. Por outro lado, uma crítica malsucedida empreendida por um comunicativo reflexivo, que agiu conforme os conselhos de seus confidentes, pode levar ao rompimento com o padrão de reflexividade anteriormente adotado. Isso porque é plausível conjecturar que conversas internas, enquanto formas de lidar com problemas (Archer, 2007: 2), sejam sensíveis ao insucesso em sua resolução. O insucesso de uma determinada performance crítica pode levar também à reavaliação de uma tática de autoconversação. Um determinado ator depois de alguma contenda pode decidir avaliar menos as situações, ser mais impulsivo ou, ao contrário, adotar uma conduta mais prudente e absorta.

Contra Boltanski e com Archer, é necessário entender que a ruptura com uma determinada situação passa por inúmeras mediações reflexivas e que a verbalização da crítica nem sempre é automática. Contra Archer e com Boltanski, é preciso compreender que nossas estratégias reflexivas - ou modos como conversamos com nós mesmos - não são padronizados, sendo sensíveis ao sucesso ou ao fracasso de nossas performances críticas. Com os dois e para além dos dois, é preciso perceber que a reflexividade e crítica são dimensões constitutivas da vida social mutuamente dependentes, ainda que não redutíveis uma a outra.

\section{Considerações finais}

Mais do que um tema específico dentre vários outros, o alcance da reflexividade nas relações sociais é um elemento a ser considerado por toda teoria social. Talvez por isso venha atraindo cada vez mais a atenção, sobretudo em contextos acadêmicos outrora resistentes ao conceito, como parece ser o caso da sociologia francesa. Nesta, as visões de Luc Boltanski sobre a capacidade crítica dos indivíduos é, sem dúvida, uma das mais destacadas. 
Contudo, é temerário chamar sua teoria social de "sociologia da capacidade crítica". Mais do que uma investigação sobre a capacidade humana de criticar, e a reflexividade que essa competência pressupõe, Boltanski dedica-se a estudos sobre a crítica em si. Logo, a capacidade crítica e a reflexividade humana operam em suas pesquisas como pressupostos teóricos, necessários para compreender as performances dos atores. Uma sociologia interessada em aferir o lugar da reflexividade no mundo moderno não pode se satisfazer em investigar as expressões dessa reflexividade em situações específicas. Mais do que isso, ela deve transformar essa reflexividade em objeto de estudo sociológico. Para tal, pode ser de grande utilidade recorrer à teoria dos modos de reflexão de Margaret Archer, para quem a reflexividade deve ser entendida como o conjunto de conversas internas que temos com nós mesmos no decorrer da vida.

De um lado, ler Boltanski à luz de Archer nos permite perceber que a expressão da crítica não encerra nossa competência de julgar a realidade. A emergência da crítica pode dispensar a expressão verbal e, ainda assim, apresentar consequências sociais consideráveis. As formas cotidianas de resistência - de que nos fala James Scott - ajudam a mostrar como uma subcultura da crítica ao poder pode engendrar uma crítica silenciosa, porém eficaz, de uma estrutura política desigual. Já a teoria da espiral ascendente do silêncio mostra como o desajuste em relação a um dado contexto pode engendrar uma performance crítica igualmente silenciosa.

Do outro lado, ler Archer à luz de Boltanski nos ajuda a perceber que o modo como refletimos sobre nossos problemas pode não ser tão estável quanto a socióloga inglesa supõe. Assim como nossa capacidade crítica é maleável, o modo como refletimos sobre situações problemáticas também o é. Ele é sensível aos sucessos e fracassos de nossas críticas e da sensação de desajuste que os momentos críticos geram. Portanto, uma sociologia da reflexividade crítica deve estar atenta não apenas à chamada crítica silenciosa, mas também ao modo como as situações problemáticas alteram a própria reflexividade humana.

Abstract: The "sociology of critical capacity" of Luc Boltanski is becoming a major paradigm in social theory. Against the understanding of reflexivity in Pierre Bourdieu critical sociology, Boltanski believes that social actors must be treated as reflexive beings, fully capable to judge and criticize the world. However, this so called "critical capacity" works in his sociology most as a theoretical premise, then as concrete object of inquiry. This text argues that a sociology interested in subjects' critical capacity cannot simply presuppose it. Most important is to constitute critical capacity as an object of sociological investigation. Redefining the human critical capacity as a reflexive competence, in Margaret Archer terms, is a useful way to do so. Archer's concepts help us to identify the limits of the Boltanski's sociology, but also, to amplify its scope.

Keywords: reflexivity; sociology of critical capacity; inner conversations; Luc Boltanski; Margaret Archer. 


\section{Referências}

ALEXANDER, Jeffrey. O novo movimento teórico. Revista Brasileira de Ciências Sociais, v. 2, n. 4, 1987.

ARCHER, Margaret Scotford. The reflexive imperative in late modernity. New York: Cambridge University Press, 2012.

. Conversations about reflexivity. Abingdon (UK); New York (NY): Routledge, 2010.

- Making our way through the world: human reflexivity and social mobility. Cambridge (MA): Cambridge University Press, 2007.

- Structure, agency, and the internal conversation. Cambridge (UK); New York (NY): Cambridge University Press, 2003.

- Being human: the problem of agency. Cambridge (UK) ; New York (NY): Cambridge University Press, 2000.

- Realist social theory: the morphogenetic approach. Cambridge (UK): Cambridge University Press, 1995.

BECK, Ulrich; GIDDENS, Anthony; LASH, Scott. Modernização reflexiva. São Paulo: Editora Unesp, 1997.

BÉNATOUİL, Thomas. A tale of two sociologies: the critical and the pragmatic stance in contemporary french sociology. European Journal of Social Theory, v. 2, n. 3, p. 379-396, 1999.

BHASKAR, Roy. Societies. In: ARCHER, Margaret Scotford; BHASKAR, Roy. Critical realism: essential readings. London; New York: Routledge, 1998.

BOLTANSKI, Luc. De la critique: précis de sociologie de l'émancipation. Paris: Gallimard, 2009.

_. El amor y la justicia como competências: tres ensayos de sociologia de la acción. Buenos Aires: Amorrortu, 1990a.

Sociologie critique et sociologie de la critique. Politix, v. 3, n. 10-11, p. 124134, $1990 b$.

_. Les cadres: la formation d'un groupe social. Paris: Éditions de Minuit, 1982. BOLTANSKI, Luc; CHIAPELLO, Ève. O novo espírito do capitalismo. São Paulo: Martins Fontes, 2009 [1999]. 
BOLTANSKI, Luc; DARRÉ, Yann; SCHILTZ, Marie-Ange. La dénonciation. Actes de la Recherche en Sciences Sociales, v. 51, p. 3-40, 1984.

BOLTANSKI, LUC; THEVENOT, Laurent. The sociology of critical capacity. European Journal of Social Theory, v. 2, n. 3, p. 359-377, 1999.

—. De la justification: les économies de la grandeur. Paris: Gallimard, 1991.

_. Justesse et justice dans le travail. Paris: PUF, 1989.

- Finding one's way in social space: a study based on games. Social Science Information, v. 22, n. 4-5, p. 631-680, 1983.

BOURDIEU, Pierre. Coisas ditas. São Paulo: Brasiliense, 2004 [1987].

CELIKATES, Robin. O não reconhecimento sistemático e a prática da crítica: Bourdieu, Boltanski e o papel da teoria crítica. Novos Estudos-Cebrap, p. 29-42, 2012.

CHIAPELLO, Eve. Reconciling the two principal meanings of the notion of ideology: the example of the concept of the "spirit of capitalism". European Journal of Social Theory, v. 6, n. 2, p. 155-171, 2003.

DODIER, Nicolas. L'espace et le mouvement du sens critique. Annales, v. 60, n. 1, 2005.

DOSSE, François. L'empire du sens: I'humanisation des sciences humaines. Paris: La Découverte, 1997.

GARFINKEL, Harold. A conception of and experiments with "trust" as a condition of stable concerted actions. In: O'BRIEN, Jodi. The production of reality: essays and readings on social interaction, p. 379-390. New York: Sage, 2010.

—. Studies in ethnomethodology. Cambridge (UK): Polity Press, 1984.

GIDDENS, Anthony. A constituição da sociedade. São Paulo: Martins Fontes, 2003 [1989].

. As consequências da modernidade. São Paulo: Editora Unesp, 1991 [1990].

LATOUR, Bruno. Reassembling the social: an introduction to actor-network-theory. Oxford (UK); New York (NY): Oxford University Press, 2005.

MEAD, George Hubert. Mind self and society: from the standpoint of a social behaviorist. Chicago: University Of Chicago Press, 1967 [1934].

NOELLE-NEUMANN, Elisabeth. The spiral of silence: public opinion - our social skin. Chicago: University of Chicago Press, 1993. 
SCOTT, James. Weapons of the weak: everyday forms of peasant resistance. New Haven (CT): Yale University Press, 2008.

. Domination and the arts of resistance: Hidden Transcripts. New Haven (CT): Yale University Press, 1990.

SEN, Amartya. Desigualdade reexaminada. São Paulo: Record, 2001.

VANDENBERGHE, Frédéric. Construção e crítica na nova sociologia francesa. Sociedade e Estado, v. 21, p. 315-366, 2006.

WALZER, Michael. Spheres of justice : a defense of pluralism and equality. New York: Basic Books, 2003 [1983]. 